\title{
Fístula biliopleural de origen traumático
}

\author{
Traumatic bilio-pleural fistula
}

Patricio Vanerio ${ }^{1}$, Nicolas Tarigo ${ }^{2}$, Juan Carlos Folonier ${ }^{3}$, Roberto Valiñas ${ }^{4}$

DOI 10.31837/cir.urug/2.2.6

Recibido: 9 de marzo de 2018

Aceptado: 26 de octubre de 2018

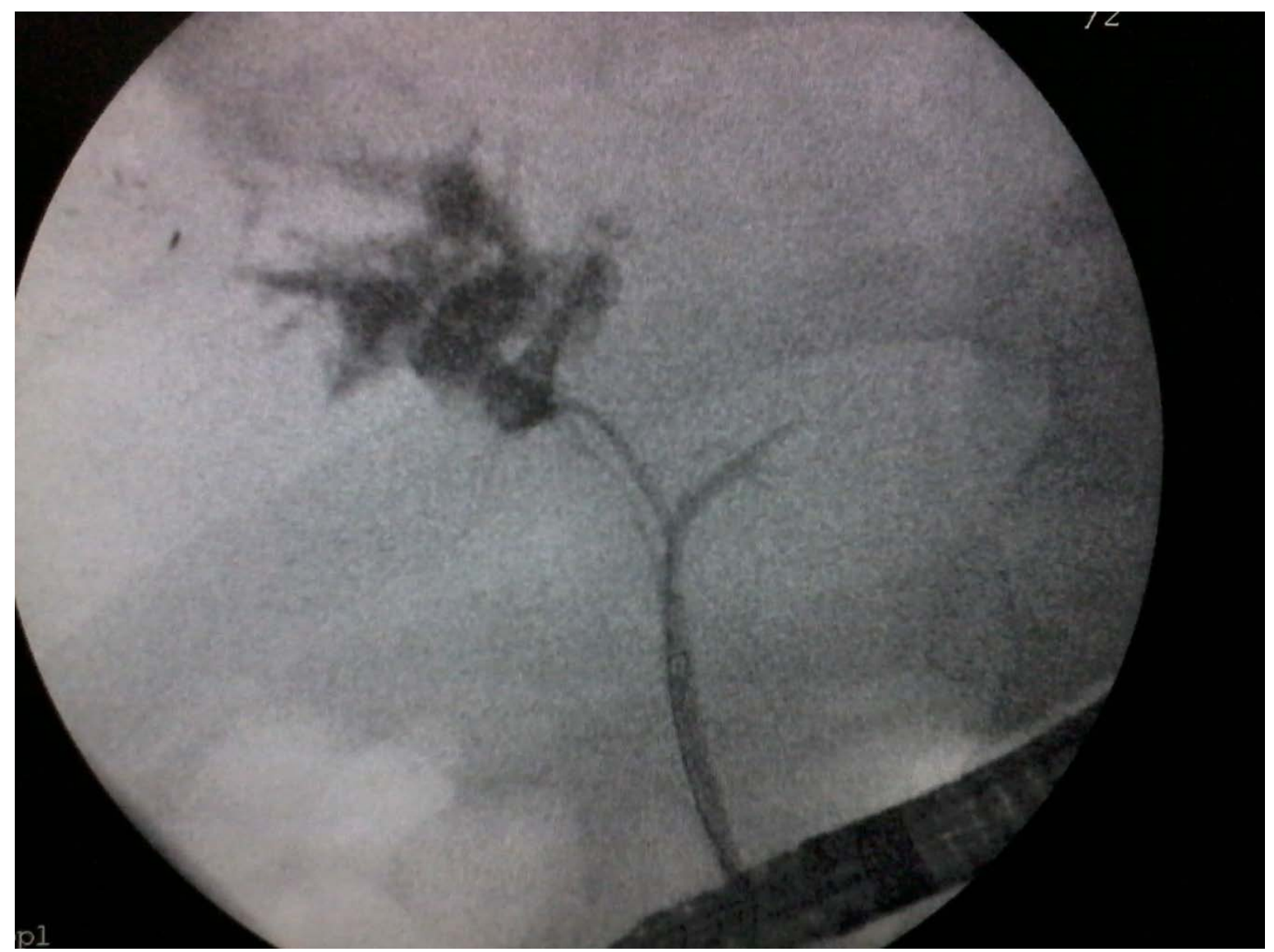

Las fístulas bilio pleurales traumáticas (FBPT) no son frecuentes. Reportamos el caso de un paciente que presentó una fistula biliopleural como complicación de una herida por arma de fuego.

1,2,3,4 Clínica Quirúrgica F, Hospital de Clínicas. Facultad de Medicina. Universidad de la República. Montevideo, Uruguay.pvanerio@gmail.com 
Paciente ingresa a emergencia presentando HPAF a nivel de región toraco-abdominal derecha, con reacción peritoneal. Drenaje pleural derecho negativo. Laparotomía exploradora: Hemoperitoneo 1000cc, se destaca lesión hepática en segmento 4b y segmento 8, y hemidiafragma derecho. No se constata sangrado en orificios hepáticos. Se coloca drenaje sub-hepático y cierre del orificio diafragmático.

Cuarenta y ocho horas del postoperatorio: bilis en drenaje pleural.

La tomografía toraco abdominal evidenció una colección en los segmentos 7 y 8 hepáticos.

Con diagnóstico de biloma intrahepático asociado a una fistula bilio pleural, se coloca un drenaje percutáneo eco-guiado a nivel de la colección y se realiza una colangiografía endoscópica retrograda (IMAGEN) donde se evidencia una lesión del conducto hepático derecho intra hepático con fuga de contraste. Se realiza una papilotomía amplia.

El paciente evoluciona favorablemente, y es dado de alta a los 15 días del ingreso sin drenajes. 